\title{
Neutron Diffraction Study of CuClTe
}

\author{
Masaki HIROTA, ${ }^{a}$ Masaji ARAI, ${ }^{a}$ Takashi SAKUMA, ${ }^{\mathrm{a}, *}$ and Yoshinobu ISHII ${ }^{\mathrm{b}}$
}

\author{
aDepartment of Physics, Faculty of Science, Ibaraki University (Mito 310-8512, Ibaraki) \\ bJapan Atomic Energy Research Institute (Tokai 319-1195, Ibaraki)
}

Received November 19, 1999 ; Accepted March 3, 2000

\begin{abstract}
The crystal structure of CuClTe has been analyzed by the Rietveld method with neutron powder diffraction data at 10 $\mathrm{K}, 290 \mathrm{~K}, 473 \mathrm{~K}$ and $633 \mathrm{~K}$. The high temperature tetragonal phase including a statistical distribution of $\mathrm{Cu}$ atoms can be maintained in CuClTe even at $10 \mathrm{~K}$. As the temperature increases, the inter atomic distances between $\mathrm{Cu} 4(\mathrm{~b})$ and $\mathrm{Cu} 16(\mathrm{~h})$ sites, $\mathrm{Cu} 16(\mathrm{~h})$ and the first nearest $\mathrm{Cu} 16(\mathrm{~h})$ sites, and $\mathrm{Cu} 16(\mathrm{~h})$ and second nearest $\mathrm{Cu} 16(\mathrm{~h})$ sites have a tendency to decrease. At high temperature $\mathrm{Cu}$ atoms would primarily diffuse through the route $4(\mathrm{~b}) \rightarrow 16(\mathrm{~h}) \rightarrow 4(\mathrm{a}) \rightarrow$ $16(\mathrm{~h}) \rightarrow 4$ (b) sites along the $c$-axis.
\end{abstract}

Key Words : Solid Electrolytes, Neutron Diffraction, Crystal Structure, Electrical Conductivity

\section{Introduction}

A group of ternary copper halide-chalcogen compounds was synthesized about thirty years ago. ${ }^{1)}$ The ionic conductivity of CuXTe $(\mathrm{X}=\mathrm{Cl}, \mathrm{Br}, \mathrm{I})$ was nearly two decades higher than that of corresponding copper halides in the temperature range $500-600 \mathrm{~K}^{2.3}$ The low temperature phase transitions of $\mathrm{CuXTe}$ have been studied by specific heat measurements, electrical conductivity measurements and X-ray diffraction measurements. ${ }^{4-6}$ ) New phase transitions in CuBrTe and CuITe were observed. The space group and the detailed atomic parameters (atomic positions, isotropic thermal parameters, occupation numbers for $\mathrm{Cu}$ sites) in CuITe at room temperature were determined. ${ }^{3}$ ) However, the detailed crystal structure of CuClTe has not been reported.

The object of the present study is to determine the detailed crystal structure of CuClTe by the Rietveld method with neutron powder diffraction data in the temperature range $10-633 \mathrm{~K}$. The temperature dependence of the crystal structure of CuClTe which would have a high temperature phase including a statistical distribution of $\mathrm{Cu}$ atoms is discussed.

\section{Experimental}

Stoichiometric quantities of copper chloride and tellurium were sealed in evacuated Pyrex tube, melted at 753 $\mathrm{K}$ for 3 hours, then annealed at $673 \mathrm{~K}$ for 1 day, $573 \mathrm{~K}$ for 3 days and $333 \mathrm{~K}$ for 1 day. The resulting compounds were crushed to a fine powder. Neutron diffraction measurements were collected from a powder CuClTe at 10 , 290,473 and $633 \mathrm{~K}$ with a triple-axis type spectrometer TAS-2 installed at JRR-3M in Japan Atomic Energy Research Institute. A vanadium container with $8 \mathrm{~mm}$ in diameter was used. The temperatures of cryostat $(10 \mathrm{~K}$, $290 \mathrm{~K})$ and electric furnace $(473 \mathrm{~K}, 633 \mathrm{~K})$ could be stabilized to within $\pm 0.2 \mathrm{~K}$. Neutron diffraction data were collected for $60 \mathrm{~s}$ per step at $0.1^{\circ}$ intervals over the $2 \theta$ range of $5^{\circ}$ to $100^{\circ}$ by a step-scan mode. The incident neutron wave length of $1.44 \AA$ was used. The obtained diffraction patterns of CuClTe are shown in Fig. 1.

The powder sample for electrical conductivity was pressed at $700 \mathrm{~kg} / \mathrm{cm}^{2}$ into cylindrical pellets $1.3 \mathrm{~cm}$ in diameter and approximately $0.14 \mathrm{~cm}$ in length. Conductive silver paint was used to attach copper leads to a sample pellet while a Hioki $3531 Z$ LCZ meter measured impedance throughout the frequency range $60 \mathrm{~Hz}-1 \mathrm{MHz}$. The conductivity of CuClTe was measured throughout the temperature interval $220 \mathrm{~K}-400 \mathrm{~K}$ and the resulting Arrhenius plot is shown in Fig. 2.

\section{Results and Discussion}

There are changes of the relative intensities in the neutron diffraction lines of CuClTe in the $2 \theta$ region of $40^{\circ}$ to $50^{\circ}$ in Fig. 1 by the change of the temperature. However, new reflections or super lattice lines did not appear at $10 \mathrm{~K}$ comparing with the reflections at 290,473 and $633 \mathrm{~K}$. Structural parameters of CuClTe were refined with RIETAN for Rietveld analysis. ${ }^{7,8}$ Structure refinements were performed by assuming that the space group of CuCrTe is $\mathrm{I} 4_{1} /$ amd. A unit cell which included $16 \mathrm{Cu}$ atoms, $16 \mathrm{Cl}$ atoms and $16 \mathrm{Te}$ atoms was applied. There are 40 sites for $16 \mathrm{Cu}$ atoms in the unit cell of CuCITe; two 4-fold sets designated 4(a), 4(b) and two 16-fold sets designated $16(\mathrm{~b})$ and $16(\mathrm{~h})$. Tables $1-4$ show the final refined structural parameters of CuClTe. The present structural model having the disordered arrangement of $\mathrm{Cu}$ atoms can sufficiently explain the observed intensities. Atomic arrangements in CuClTe are shown in Fig.3. The pyroelectricity and the piezolelectricity for CuClTe are not expected to be observed. It is very rare that the high temperature phase including a statistical distribution of atoms can be maintained at $10 \mathrm{~K}$. Typical copper halides $\left.(\mathrm{CuCl}, \mathrm{CuBr}, \mathrm{CuI})^{9}\right)^{\prime}$ and $\mathrm{CuXTe}(\mathrm{X}=\mathrm{Br}, \mathrm{I})$ undergo phase transitions from disordered arrangement of $\mathrm{Cu}$ atoms to ordered arrangements. In the case of ternary silver halide-chalcogen compounds $\left(\mathrm{Ag}_{3} \mathrm{SI}, \mathrm{Ag}_{3} \mathrm{SBr}\right.$, 

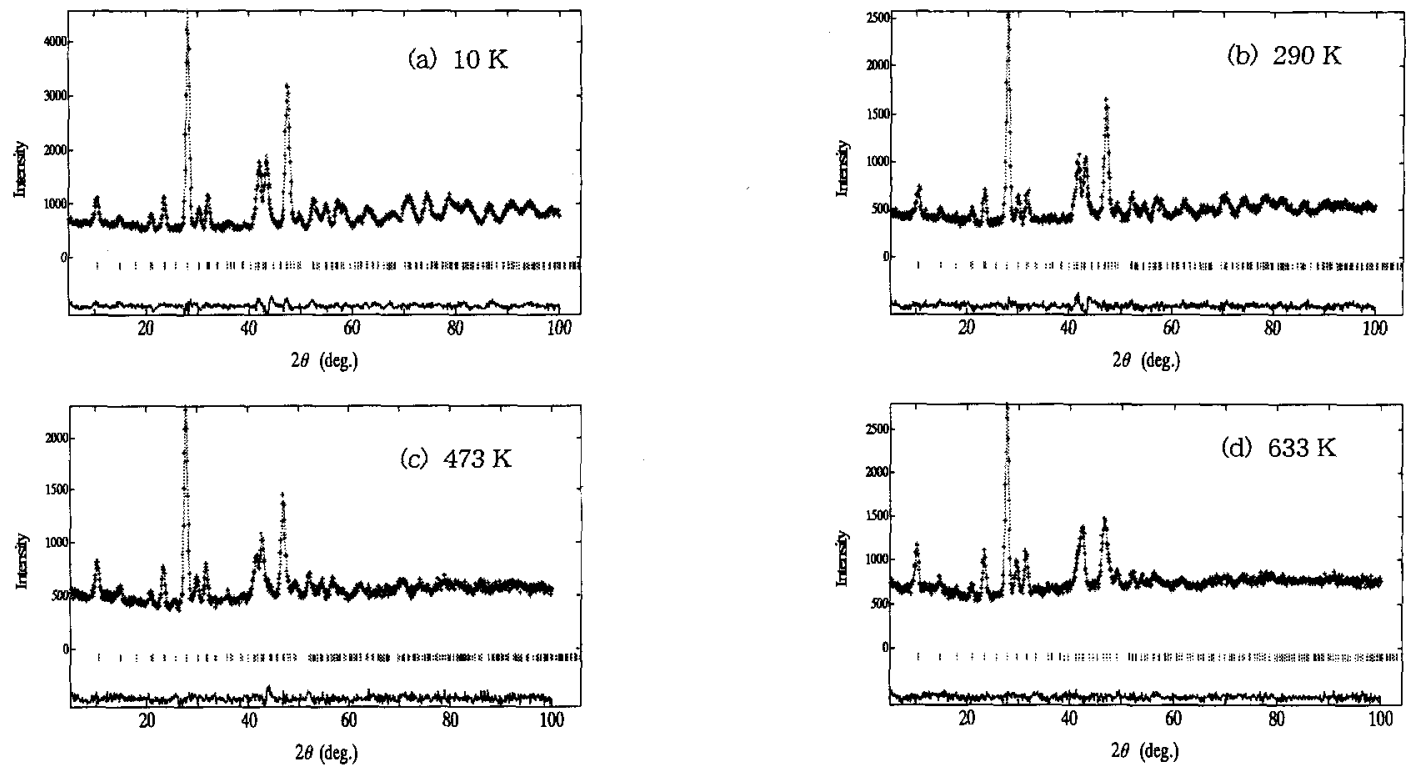

Fig. 1 Rietveld refinement patterns for CuClTe. The broken lines are calculated intensities, the crosses $(+)$ are observed intensities, and solid lines are the differences between calculated and observed intensities. The short vertical lines mark the positions of possible Bragg diffraction. (a) $10 \mathrm{~K}$, (b) $290 \mathrm{~K}$, (c) $473 \mathrm{~K}$, (d) $633 \mathrm{~K}$.

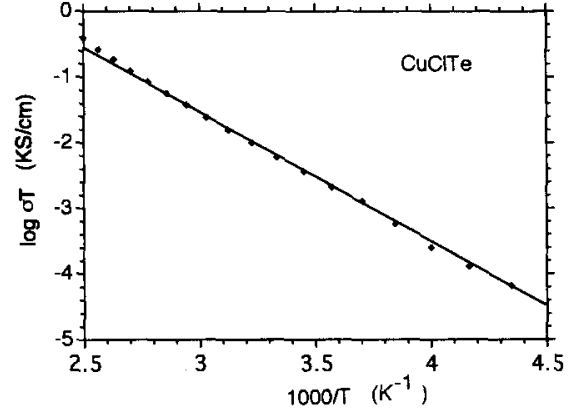

Fig. 2 Arrhenius plot of the electrical conductivity of CuClTe.

$\left.\mathrm{Ag}_{3} \mathrm{SBr}_{0.5} \mathrm{I}_{0.5}\right)$ also undergo clear phase transitions from disordered arrangement of $\mathrm{Ag}$ atoms to ordered arrangements. ${ }^{9)}$

The occupation numbers for $\mathrm{Cu}$ sites in Tables 1-4 change rapidly by the change of temperature from $473 \mathrm{~K}$

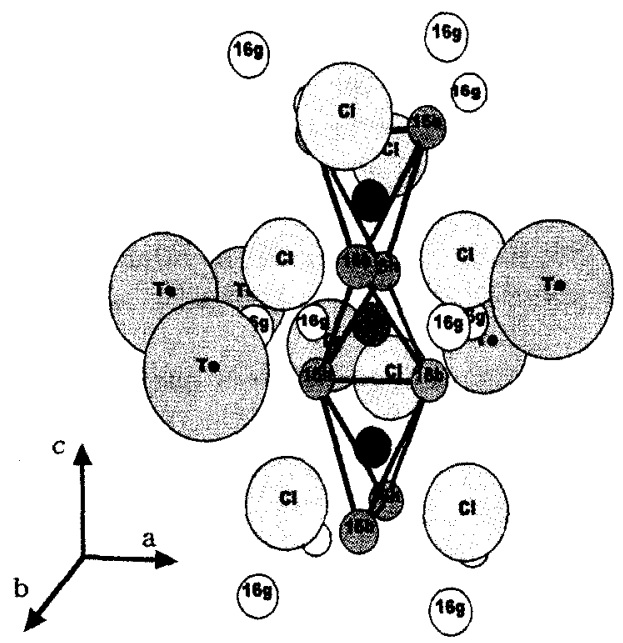

$10 \mathrm{~K}$ to $633 \mathrm{~K}$; the occupation numbers for $4(\mathrm{~b})$ and $16(\mathrm{~g})$ sites decrease and those for $4(\mathrm{a})$ and $16(\mathrm{~h})$ sites increase. The values of temperature parameters $B$ for $\mathrm{Cu}, \mathrm{Cl}$ and Te atoms increase as the temperature increases. The obtained values of temperature parameters for $\mathrm{Cu}$ atoms from Rietveld analysis are very large even at $10 \mathrm{~K}$. However this would not show that the atomic vibrations of $\mathrm{Cu}$ atoms are very large at $10 \mathrm{~K}$. The present structure model includes only $4(\mathrm{a}), 4(\mathrm{~b}), 16(\mathrm{~g})$ and $16(\mathrm{~h}) \mathrm{Cu}$ sites. In practice a part of $\mathrm{Cu}$ atoms would be distributed on the other atomic positions leaving these $\mathrm{Cu}$ sites. The effect of the distribution of $\mathrm{Cu}$ atoms on other atomic positions would be included in the values of temperature parameters of $\mathrm{Cu}$ atoms at all temperatures. The probable atomic sites for $\mathrm{Cu}$ atoms are 8(e), 8(e), 16(h) and 32(i) $\mathrm{Cu}$ sites. $4(\mathrm{a}), 4(\mathrm{~b})$ and $16(\mathrm{~g})$ sites are special positions of $8(\mathrm{e}), 8(\mathrm{e})$ and $32(\mathrm{i})$ sites, respectively. In our recent

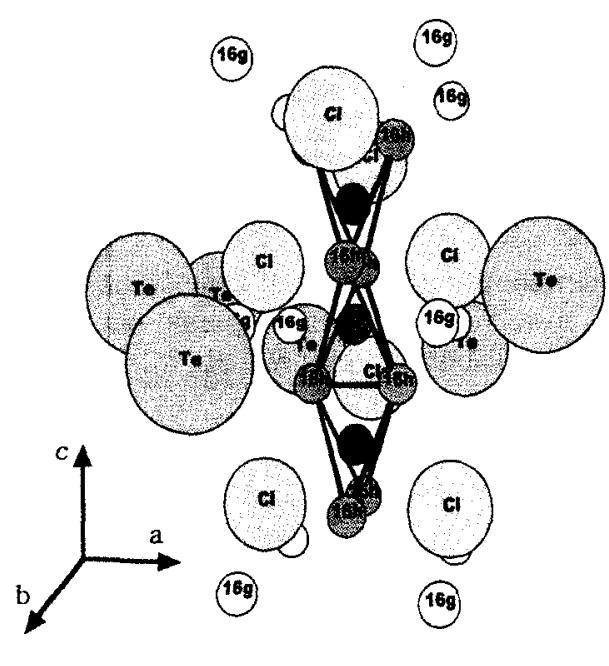

$633 \mathrm{~K}$

Fig. 3 Atomic arrangements in CuClTe. (a) $10 \mathrm{~K}$, (b) $633 \mathrm{~K}$. 
test for the structural analysis of $\alpha$-CuBrTe, the values of reliability factors with a disordered model including 8(e), 8(e), 16(h) and 32(i) $\mathrm{Cu}$ sites are less than those including 4(a), 4(b), 16(g) and $16(\mathrm{~h}) \mathrm{Cu}$ sites. The values of lattice constant $a$ show clear temperature dependence which is in contrast to a small change of lattice constant $c$ in Tables 1-4.

Temperature change of values of $\mathrm{Te}-\mathrm{Cu} 16(\mathrm{~g})$ and $\mathrm{Te}-$ Te bond lengths in CuClTe is small. The calculated val-

Table 1 Structural parameters of CuClTe at $10 \mathrm{~K}$. The coordinates $x, y, z$, isotropic thermal parameter $B$, lattice constants $a, c$ and reliability factors $R_{w p}, R_{p}, R_{e}, R_{I}, R_{F}$.

\begin{tabular}{ccclllcc}
\hline Atom & Position & Occupation & \multicolumn{1}{c}{$x$} & \multicolumn{1}{c}{$y$} & \multicolumn{1}{c}{$z$} & $B\left(\AA^{2}\right)$ \\
\hline $\mathrm{Cu}$ & $4 \mathrm{a}$ & 0.03 & 0.0 & 0.75 & 0.125 & 2.74 \\
& $4 \mathrm{~b}$ & 0.77 & 0.0 & 0.25 & 0.375 & 3.22 \\
& $16 \mathrm{~g}$ & 0.72 & 0.127 & 0.377 & 0.875 & 1.72 \\
& $16 \mathrm{~h}$ & 0.08 & 0.0 & 0.168 & 0.651 & 1.68 \\
$\mathrm{Cl}$ & $16 \mathrm{~h}$ & 1.0 & 0.0 & 0.119 & 0.126 & 0.15 \\
$\mathrm{Te}$ & $16 \mathrm{f}$ & 1.0 & 0.137 & 0.0 & 0.0 & 0.30 \\
\hline
\end{tabular}

$a=15.537 \AA, c=4.799 \AA$,

$R_{w p}=5.1 \%, R_{p}=4.0 \%, R_{e}=3.5 \%, R_{I}=2.6 \%, R_{F}=1.6 \%$

Table 2 Structural parameters of CuClTe at $290 \mathrm{~K}$. The coordinates $x, y, z$, isotropic thermal parameter $B$, lattice constants $a, c$ and reliability factors $R_{w p}, R_{p}, R_{e}, R_{I}, R_{F}$.

\begin{tabular}{cccccccc}
\hline Atom & Position & Occupation & \multicolumn{1}{c}{$x$} & \multicolumn{1}{c}{$y$} & \multicolumn{1}{c}{$z$} & $B\left(\AA^{2}\right)$ \\
\hline $\mathrm{Cu}$ & $4 \mathrm{a}$ & 0.5 & 0.0 & 0.75 & 0.125 & 3.21 \\
& $4 \mathrm{~b}$ & 0.79 & 0.0 & 0.25 & 0.375 & 4.68 \\
& $16 \mathrm{~g}$ & 0.71 & 0.126 & 0.376 & 0.875 & 3.26 \\
& $16 \mathrm{~h}$ & 0.08 & 0.0 & 0.169 & 0.69 & 3.25 \\
$\mathrm{Cl}$ & $16 \mathrm{~h}$ & 1.0 & 0.0 & 0.118 & 0.128 & 1.23 \\
$\mathrm{Te}$ & $16 \mathrm{f}$ & 1.0 & 0.137 & 0.0 & 0.0 & 0.72 \\
\hline
\end{tabular}

$a=15.637 \AA, c=4.818 \AA$,

$R_{w p}=5.4 \%, R_{p}=4.2 \%, R_{e}=4.3 \%, R_{I}=3.9 \%, R_{F}=2.4 \%$

Table 3 Structural parameters of CuCrTe at $473 \mathrm{~K}$. The coordinates $x, y, z$, isotropic thermal parameter $B$, lattice constants $a, c$ and reliability factors $R_{w p}, R_{p}, R_{e}, R_{I}, R_{F}$.

\begin{tabular}{ccccccc}
\hline Atom & Position & Occupation & \multicolumn{1}{c}{$x$} & \multicolumn{1}{c}{$y$} & \multicolumn{1}{c}{$z$} & $B\left(\AA^{2}\right)$ \\
\hline $\mathrm{Cu}$ & $4 \mathrm{a}$ & 0.07 & 0.0 & 0.75 & 0.125 & 5.60 \\
& $4 \mathrm{~b}$ & 0.57 & 0.0 & 0.25 & 0.375 & 5.17 \\
& $16 \mathrm{~g}$ & 0.70 & 0.125 & 0.375 & 0.875 & 5.30 \\
& $16 \mathrm{~h}$ & 0.14 & 0.0 & 0.197 & 0.625 & 5.25 \\
$\mathrm{Cl}$ & $16 \mathrm{~h}$ & 1.0 & 0.0 & 0.119 & 0.125 & 2.86 \\
$\mathrm{Te}$ & $16 \mathrm{f}$ & 1.0 & 0.14 & 0.0 & 0.0 & 2.11 \\
\hline
\end{tabular}

$a=15.703 \AA, c=4.803 \AA$,

$R_{w p}=4.8 \%, R_{p}=3.8 \%, R_{e}=4.2 \%, R_{I}=6.1 \%, R_{F}=3.8 \%$

Table 4 Structural parameters of CuClTe at $633 \mathrm{~K}$. The coordinates $x, y, z$, isotropic thermal parameter $B$, lattice constants $a, c$ and reliability factors $R_{w p}, R_{p}, R_{e}, R_{I}, R_{F}$.

\begin{tabular}{cccccccc}
\hline Atom & Position & Occupation & \multicolumn{1}{c}{$x$} & \multicolumn{1}{c}{$y$} & $\boldsymbol{z}$ & $B\left(\AA^{2}\right)$ \\
\hline $\mathrm{Cu}$ & $4 \mathrm{a}$ & 0.13 & 0.0 & 0.75 & 0.125 & 5.49 \\
& $4 \mathrm{~b}$ & 0.46 & 0.0 & 0.25 & 0.375 & 5.37 \\
& $16 \mathrm{~g}$ & 0.65 & 0.128 & 0.378 & 0.875 & 5.81 \\
& $16 \mathrm{~h}$ & 0.20 & 0.0 & 0.19 & 0.628 & 5.97 \\
$\mathrm{Cl}$ & $16 \mathrm{~h}$ & 1.0 & 0.0 & 0.119 & 0.124 & 4.39 \\
$\mathrm{Te}$ & $16 \mathrm{f}$ & 1.0 & 0.139 & 0.0 & 0.0 & 3.54
\end{tabular}

$a=15.869 \AA, c=4.789 \AA$,

$R_{w p}=4.0 \%, R_{p}=3.1 \%, R_{e}=3.6 \%, R_{I}=6.3 \%, R_{F}=4.9 \%$ ues of Te-Cu $16(\mathrm{~g})$ and Te-Te bond lengths in CuClTe at $10 \mathrm{~K}$ are 2.63 and $2.75 \AA$, respectively. The values at 633 $\mathrm{K}$ are 2.64 and $2.77 \AA$. It is possible that the atomic types of the neighbors of the tellurium atoms are tellurium atoms in copper halide-chalcogen compounds. The tellurium atoms in CuClTe form infinite helical chains that are known in metallic tellurium. The $\mathrm{Cl}$ atoms keep off other $\mathrm{Cl}$ atoms, and the nearest neighbors of $\mathrm{Cl}$ atoms are $\mathrm{Cu}$ atoms because of attractive forces between them. The nature of a bond between $\mathrm{Cu}$ and $\mathrm{Cl}$ atoms may be ionic, and that between tellurium atoms covalent. In the case of $\mathrm{Ag}_{3} \mathrm{SI}$, which is a well known ternary silver halide-chalcogen compound, the formal charges of $\mathrm{Ag}, \mathrm{S}$ and $I$ are $+1,-2$ and -1 , respectively. ${ }^{10)}$ The sulphur atoms keep off other sulphur atoms in the silver halidechalcogen compounds. On the contrary, it is possible that the atomic types of the nearest neighbors of the tellurium atoms are tellurium atoms in copper halidechalcogen compounds.

The calculated inter atomic distances from the atomic positions, which show apparent temperature dependence, are given in Table 5 . The inter atomic distances between $\mathrm{Cu}$ 4(b) and $\mathrm{Cu}$ 16(h) sites (r), $\mathrm{Cu} \mathrm{16(h)} \mathrm{and} \mathrm{the} \mathrm{first}$ nearest $\mathrm{Cu} 16(\mathrm{~h})$ sites $\left(r_{1}\right)$, and $\mathrm{Cu} 16(\mathrm{~h})$ and second nearest $\mathrm{Cu} 16(\mathrm{~h})$ sites $\left(r_{2}\right)$ have a tendency to decrease. The values of $r_{1}$ and $r_{2}$ are sides of tetrahedron which surrounds $\mathrm{Cu}$ 4(b) site in Fig.3. This shows that the volume of tetrahedron formed by four $\mathrm{Cu} 16(\mathrm{~h})$ sites decreases although the volume of unit cell increases with temperature. At $10 \mathrm{~K}$ the volume of tetrahedron which surrounds $4(\mathrm{~b})$ site $\left(2.874 \AA^{3}\right)$ is greater than that of the tetrahedron for 4 (a) site $\left(2.332 \AA^{3}\right)$. The volume of tetrahedron for $4(\mathrm{~b})$ site $\left(1.464 \AA^{3}\right)$ is almost same as that of 4 (a) site $\left(1.430 \AA^{3}\right)$ at $633 \mathrm{~K}$.

From the conductivity measurement of $\mathrm{CuClTe}$ throughout the temperature interval $220 \mathrm{~K}-400 \mathrm{~K}$, an anomaly of electrical conductivity was not observed in Fig.2. The obtained value of the electrical conductivity at room temperature coincides with that of the former reports above room temperature. ${ }^{2)}$ An estimate of the activation energy $E$ can be made by fitting acquired data for CuClTe to the expression $\sigma T=A_{0} \exp (-E / k T)$. The value of $0.42 \mathrm{eV}$ for the activation energy of CuClTe was estimated. The solid lines in Fig.2 associated with the CuClTe are a least-square fit of the data. $4(\mathrm{a}), 4(\mathrm{~b}), 16(\mathrm{~h})$ $\mathrm{Cu}$ sites are surrounded with a tetrahedron which is constructed form four $\mathrm{Cl}$ atoms. $\mathrm{Cu}$ atoms would diffuse from a $\mathrm{Cu}$ site in one tetrahedron to other $\mathrm{Cu}$ site in the nearest tetrahedron through a triangular surface which is

Table 5 Temperature dependence of inter atomic distances

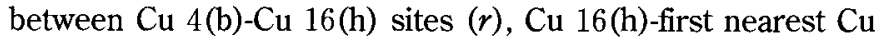
16(h) sites $\left(r_{1}\right)$ and $\mathrm{Cu} 16(\mathrm{~h})$-second nearest $\mathrm{Cu} 16(\mathrm{~h})$ sites $\left(r_{2}\right)$.

\begin{tabular}{|c|c|c|c|}
\hline & $\begin{array}{c}r(\AA) \\
\mathrm{Cu} 4(\mathrm{~b})-\mathrm{Cu} 16(\mathrm{~h})\end{array}$ & $\begin{array}{c}n_{1}(\AA) \\
\mathrm{Cu} 16(\mathrm{~h})-\mathrm{Cu} 16(\mathrm{~h})\end{array}$ & $\begin{array}{c}r_{2}(\AA) \\
\mathrm{Cu} 16(\mathrm{~h})-\mathrm{Cu} 16(\mathrm{~h})\end{array}$ \\
\hline $10 \mathrm{~K}$ & 1.84 & 2.56 & 3.21 \\
\hline $290 \mathrm{~K}$ & 1.98 & 2.53 & 3.53 \\
\hline $473 \mathrm{~K}$ & 1.46 & 1.67 & 2.67 \\
\hline $633 \mathrm{~K}$ & 1.52 & 1.91 & 2.78 \\
\hline
\end{tabular}


decided by three $\mathrm{Cl}$ atoms. There is not very much change in the triangular surface with temperature. The estimated value of the activated energy from Fig. 2 was $0.42 \mathrm{eV}$ throughout the temperature interval $200 \mathrm{~K}-400 \mathrm{~K}$. It would suggest that the value of the activation energy is mainly affected by the triangular surface decided by $\mathrm{Cl}$ atoms. The change of the activation energy has not been observed in the $\alpha$-phase of copper halidechalcogen solid electrolytes. In the case of CulTe ${ }^{6}$, the activation energy was $0.57 \mathrm{eV}$ throughout the $\alpha$ - and $\beta$-phases. To estimate the change of activation energy in CuClTe in detail, we need a measurement of the electrical conductivity over a wide temperature range. The electric conductivity would be related to a statistical occupation of $\mathrm{Cu}$ atoms. $\mathrm{Cu}$ atoms would diffuse in CuClTe through the disordered $\mathrm{Cu}$ sites. As the temperature increases, the distance between $4(\mathrm{~b})$ and $16(\mathrm{~h})$ sites decreases from 1.9 to $1.5 \AA$ in Table 5 . The increase of the electrical conductivity would be related to the decrease in the distance between 4(b) and 16(h) sites. From the distances between neighboring atoms at high temperature $\mathrm{Cu}$ atoms would primarily diffuse through the route $4(\mathrm{~b}) \rightarrow 16(\mathrm{~h}) \rightarrow 4$ (a) $\rightarrow$ $16(\mathrm{~h}) \rightarrow 4(\mathrm{~b})$ sites along the $c$-axis. As the crystal struc- ture of CuClTe belongs to tetragonal system, the electrical conductivity would show anisotropic properties. To study further details of the dynamical behavior of CuClTe, the single crystal is required.

\section{References}

1) A. Rabenau, Solid State Ionics, 6, 277 (1982).

2) U. von Alpen, J. Fenner, J. Marcoll, and A. Rabenau, Electrochimica Acta , 22, 801 (1977).

3) J. Fenner, A. Rabenau, and G. Schluckerbier, Z. anorg. allg. Chem., 426, 7 (1976).

4) T. Sakuma, T. Kaneko, H. Takahashi, and K. Honma, J. Phys. Soc. Japan, 60, 1136 (1991).

5) A. Murakami, T. Sakuma, H. Takahashi, and Y. Onoda, $J$. Phys. Soc. Japan, 67, 502 (1998).

6) R. B. Beeken, J. Dean, W. Jetzer, D. Lee and T. Sakuma, Solid State Ionics, 58, 189 (1992).

7) F. Izumi, The Rietveld Method (Ed. R. A. Young) , Chap. 13, Oxford University Press, Oxford, (1993).

8) Y. I. Kim and F. Izumi, J. Ceram. Soc. Japan, 102, 401 (1994).

9) S Hoshino, Solid State Ionics , 48, 179 (1991).

10) T. Sakuma, B. Electrochem., 11, 57 (1995). 